\title{
Optimization of steel penstock in a bored tunnel
}

\author{
S. Kravanja \\ University of Maribor, Faculty of Civil Engineering, Maribor, Slovenia
}

\begin{abstract}
This paper presents the optimization of steel penstock, designed to be built in a bored tunnel. The optimization was performed by the non-linear programming (NLP) approach. For this purpose, the NLP optimization model was developed. The model comprises the mass objective function, which is subjected to design and dimensioning constraints. The dimensioning constraints were defined according to C.E.C.T. recommendations. The penstock was designed without stiffener rings and without collaboration of the surrounding rock. Numerical example of the penstock optimization, planned to be made for the hydropower plant Kozjak in Slovenia, demonstrates the efficiency of the introduced optimization approach.
\end{abstract}

Keywords: steel penstock, steel liner, bored tunnel, optimization, non-linear programming, NLP.

\section{Introduction}

The paper deals with the optimization of a steel penstock, built in a tunnel, which is bored into the rock environment. The penstock was designed in order to provide the water for a pumped storage power plant. The optimization was performed by the non-linear programming (NLP) approach. The NLP optimization model was developed.

The penstock was designed as a circular steel liner without stiffener rings and without collaboration of the rock. In this way, the penstock is designed to be self-resistant, without taking into account the contribution of the surrounding rock. Since the optimization was proposed to be performed for the phase of the conceptual design, only some basic constraints were defined in the optimization model in order to assure enough strength and stability of the steel liner. The 
model comprises the mass objective function, which is subjected to the design and dimensioning constraints. The dimensioning constraints were defined according to C.E.C.T. recommendations [1].

Two load cases on the pipe were taken into account. The first one is the internal water pressure, caused by the filling the penstock with the water. The dynamical effect of the water hammer was also considered. The second load case represents the external water pressure, which was calculated to be equal to the height of external ground-water.

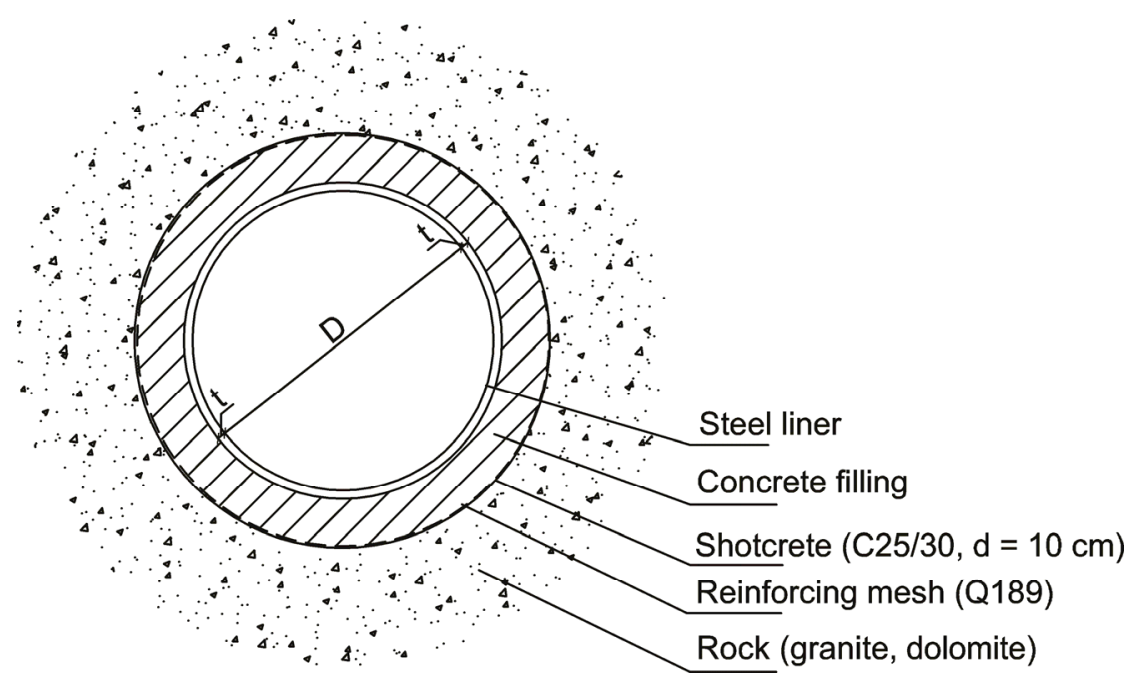

Figure 1: Cross-section of the steel penstock.

The construction of such steel penstocks is typical. It comprises the tunnelling, the fabrication of steel sections and the installation. A tunnel is bored in order to transport pipe sections and concrete as well as allow the access for machinery during the construction of the pipe. The excavation of a tunnel is done by tunnel boring machines. In this way, a tube-like passage is dug through the rock. The tunnel walls are then strengthened with shotcrete and the reinforcing meshes. The steel structure may be fabricated in the factory or on the field near the construction site. The fabrication includes cutting the plates to design dimensions, preparing the edges for welding, pressing and rolling the plates to the required radius and welding the plates together into penstock sections. In order to obtain a "light" structure, high strength steels are recommended for use. The penstock sections are usually transported to the place of installation by truck or trailer and lifted in place by cableway or crane. After the pipe sections are set to line and graded on temporary supports, they are first tack-welded together, then the joints are completed by the automatic welding machines. The welds must be inspected by radiography. At the end, the annular space between the steel pipe and the rock is filled by the self-placed concrete (see Figure 1). 


\section{NLP problem formulation}

Since the optimization problem of the steel penstock is non-linear, the optimization is performed by the non-linear optimization (NLP) approach. The general NLP optimization problem can be formulated as follows:

$$
\begin{gathered}
\min z=f(\boldsymbol{x}) \\
\text { subjected to: } \\
\boldsymbol{h}(\boldsymbol{x})=\mathbf{0} \\
\boldsymbol{g}(\boldsymbol{x}) \leq \mathbf{0}
\end{gathered}
$$

where $\boldsymbol{x}$ is a vector of continuous variables, defined within the compact set $X$. Functions $f(\boldsymbol{x}), \boldsymbol{h}(\boldsymbol{x})$ and $\boldsymbol{g}(\boldsymbol{x})$ are nonlinear functions involved in the objective function $z$, equality and inequality constraints, respectively. All functions $f(\boldsymbol{x})$, $\boldsymbol{h}(\boldsymbol{x})$ and $\boldsymbol{g}(\boldsymbol{x})$ must be continuous and differentiable.

In the context of structural optimization, variables include dimensions, crosssection characteristics, strains, materials, stresses, economic parameters, etc. Equality and inequality constraints and the bounds of the variables represent a rigorous system of the design, loading, stress, resistance and deflections functions taken from structural analysis and the dimensioning. In this paper, a mass objective function is proposed to minimize the mass of the steel structure.

\section{The optimization model PIPEOPT}

According to the above NLP problem formulation, an NLP optimization model PIPEOPT was developed for the optimization of the steel pipe liner. As an interface for mathematical modelling and data inputs/outputs GAMS (General Algebraic Modelling System), a high level language [2], was used. The proposed optimization model includes input data (constants), variables and cost objective function of the pipe section, subjected to the design and stability constraints. The constraints for the stability of the steel liner are defined according to C.E.C.T. recommendations.

Input data represent design data (constants) for the optimization. A steel wall thickness $t[\mathrm{~cm}]$, a theoretical pipe wall thickness $e[\mathrm{~cm}]$, a normal circumferential stress in the pipe $\sigma_{N}\left[\mathrm{kN} / \mathrm{cm}^{2}\right]$ and critical pressure $p_{c r}^{-i}\left[\mathrm{kN} / \mathrm{cm}^{2}\right]$ for a pipe without stiffeners are defined as the design variables.

The objective function comprises the mass of the circular steel pipe section (see eqn. (1)):

$$
\text { mass }=\pi \cdot t \cdot(2 \cdot R+t) \cdot \rho \cdot L_{\text {sect }}
$$


where the objective variable mass $[\mathrm{kg}]$ represents the mass of the steel pipe section, $t[\mathrm{~cm}]$ stands for the pipe wall thickness, $R[\mathrm{~cm}]$ is the internal radius of the pipe, $\rho\left[\mathrm{kg} / \mathrm{cm}^{3}\right]$ denotes the unit mass of steel $\left(0.00785 \mathrm{~kg} / \mathrm{cm}^{3}\right)$ and $L_{\text {sect }}$ $[\mathrm{cm}]$ is the length of the pipe section.

The theoretical wall thickness $e[\mathrm{~cm}]$ is the wall thickness $t[\mathrm{~cm}]$, decreased by the corrosion allowance $\operatorname{cor}[\mathrm{cm}]$, see eqn. (2):

$$
e=t-c o r
$$

Eqn. (3) defines the minimal theoretical wall thickness $e$ [cm] for the case when the penstock is exposed to the internal water pressure load case. The biaxial stress state in the pipe wall is considered, because the longitudinal contraction of the pipe, caused by the internal pressure, is prevented by the surrounding filled concrete.

$$
e \geq \frac{0.89 \cdot C_{i p} \cdot p_{i n} \cdot R}{f_{y}}
$$

where $C_{i p}$ is a safety factor relative to the internal water pressure [-], $p_{i n}\left[\mathrm{kN} / \mathrm{cm}^{2}\right]$ represents the value of the internal water pressure, $R[\mathrm{~cm}]$ is the internal radius of the pipe and $f_{v}\left[\mathrm{kN} / \mathrm{cm}^{2}\right]$ stands for the yield strength of the steel.

The steel liner is stable if both the constraints (4) and (5) are simultaneously fulfilled by a normal circumferential stress in the pipe $\sigma_{N}\left[\mathrm{kN} / \mathrm{cm}^{2}\right]$.

$$
12 \cdot\left(\frac{R+e}{e}\right)^{2} \cdot\left(\sigma_{N}+E^{*} \cdot \frac{j}{R}\right) \cdot\left(\frac{\sigma_{N}}{E^{*}}\right)^{3 / 2} \leq f_{y}-\sigma_{N}
$$

where:

$$
\begin{gathered}
E^{*}=E /\left(1-v^{2}\right) \\
j / R=1.0 \% \text { o }=0.001 \\
p_{c r}^{-i}=\sigma_{N} \cdot \frac{e}{R+e} \cdot\left(1+0.35 \cdot \frac{R+e}{e} \cdot \frac{f_{y}-\sigma_{N}}{E^{*}}\right)^{-1}
\end{gathered}
$$

where $\mathrm{E}\left[\mathrm{kN} / \mathrm{cm}^{2}\right]$ is modulus of elasticity for steel $\left(21000 \mathrm{kN} / \mathrm{cm}^{2}\right), v[-]$ is Poisson factor $(0.3), \mathrm{j} / \mathrm{R}[-]$ represents the interstitial clearance immediately after draining and $p_{c r}^{-i}\left[\mathrm{kN} / \mathrm{cm}^{2}\right]$ stands for the critical pressure for a pipe without stiffeners and having an ideal shape.

The normal circumferential stress in the pipe $\sigma_{N}$ is in addition constrained by eqn. (6):

$$
\sigma_{N} \leq \varphi \cdot f_{y}
$$


where $\varphi[-]$ represents the coefficient, which define the highest normal stress for which the structure still meets the requirements of the Hooke law (0.7).

Finally, the critical pressure $p_{c r}^{-i}\left[\mathrm{kN} / \mathrm{cm}^{2}\right]$ must be greater than the design external water pressure, see eqn. (7):

$$
p_{c r}^{-i} \geq C_{e p} \cdot p_{e x}
$$

where $C_{e p}$ is a safety factor relative to the external water pressure [-] and $p_{e x}$ $\left[\mathrm{kN} / \mathrm{cm}^{2}\right]$ represents the value of the external water pressure on pipe.

\section{Numerical example - hydropower plant Kozjak}

A proposed numerical example represents the optimization of steel penstock, planed to be made for hydropower plant Kozjak in Slovenia, located in the northeast part of the Republic of Slovenia, $15 \mathrm{~km}$ far from the city of Maribor. The pumped storage hydroelectric power plant Kozjak comprises a water reservoir of 3 million $\mathrm{m}^{3}$ (already constructed), $2400 \mathrm{~m}$ long steel penstock, gross head more than $700 \mathrm{~m}$, net capacity 2 × $220 \mathrm{MW}$ and 2 Francis-reversible turbines.

Company IBE from Ljublana made the conceptual design for the power plant Kozjak and also performed a penstock dimensioning [3] in May 2011. Structural steel S 460 was proposed to be used. The steel pipe mass of 12751.98 tons was determined for Variant 1. A number of variants of pipes were considered and dimensioned. Vertical variant was designed in March 2012 [4].

The NLP optimizations of the penstock variants were then performed at the Faculty of Civil Engineering, University of Maribor, from September 2011 [5] to July 2012 [6]. The optimization model PIPEOPT was applied. Structural steel S690 Q was considered (yield strength $f_{y}=69.0 \mathrm{kN} / \mathrm{cm}^{2}$ ). Two variants are proposed to be presented in the paper: the longest inclined variant - the variant 1 and the shortest variant - the vertical penstock.

\subsection{Variant 1}

The variant 1 (with asynchronous generator) is designed to be $2471.03 \mathrm{~m}$ long steel penstock. Since two $67.97 \mathrm{~m}$ long vertical sections are constructed from the minimal possible thickness, only the penstock in length of $2335.09 \mathrm{~m}$ is included in the optimization. Steel S690 Q was considered. Input data comprise internal diameters $D$ from $3.90 \mathrm{~m}$ to $4.30 \mathrm{~m}$, pipe section lengths $L_{\text {sect }}$ from $144.10 \mathrm{~m}$ to $619.78 \mathrm{~m}$, the corrosion allowance cor $=0.2 \mathrm{~cm}$, yield strength $f_{y}=65.0 \mathrm{kN} / \mathrm{cm}^{2}$, safety factor relative to the internal water pressure $C_{i p}=1.50$, safety factor relative to the external water pressure $C_{e p}=1.80$, maximal internal water pressure $p_{\text {in }}=1028.30 \mathrm{kN} / \mathrm{cm}^{2}(102.83$ bars $)$ as well as maximal external water pressure $p_{e x}=463.88 \mathrm{kN} / \mathrm{cm}^{2}$ (46.38 bars).

Seven different pipe sections of different diameters and lengths were optimized. Since the NLP model PIPEOPT is non-linear, the optimization was performed by the computer code GAMS/CONOPT2 (the general reduced 
gradient method) [7]. The optimal result represents the obtained penstock's minimal mass of 9967.40 tons and the calculated wall thicknesses from $20 \mathrm{~mm}$ to $63 \mathrm{~mm}$ (see Table 1). Cross-section through the first pipe section is shown in Figure 2.

Table 1: $\quad$ Optimized mass of the penstock - Variant 1.

\begin{tabular}{|r|r|r|r|r|r|r|}
\hline $\mathrm{x}(\mathrm{m})$ & \multicolumn{1}{|c|}{$\mathrm{p}_{\text {in }}(\mathrm{m})$} & $\mathrm{p}_{\text {ex }}(\mathrm{m})$ & $\mathrm{D}(\mathrm{m})$ & $\mathrm{t}(\mathrm{mm})$ & \multicolumn{1}{c|}{$\mathrm{L}_{\text {sect }}(\mathrm{m})$} & \multicolumn{1}{c|}{$\Sigma(\mathrm{kg})$} \\
\hline 0.00 & 1028.30 & 150.00 & 3.90 & 41 & 144.10 & 574214 \\
\hline 108.15 & 926.19 & 200.00 & 3.90 & 37 & 356.87 & 1282025 \\
\hline 465.00 & 885.62 & 348.53 & 3.90 & 50 & 465.02 & 2264948 \\
\hline 930.00 & 832.76 & 463.88 & 4.10 & 63 & 363.66 & 2352133 \\
\hline 1205.00 & 589.65 & 369.28 & 4.10 & 55 & 385.66 & 2173490 \\
\hline 1480.00 & 293.91 & 42.06 & 4.30 & 20 & 619.78 & 1320598 \\
\hline Total: & & & & & 2335.09 & $\mathbf{9 9 6 7 4 0 8}$ \\
\hline
\end{tabular}

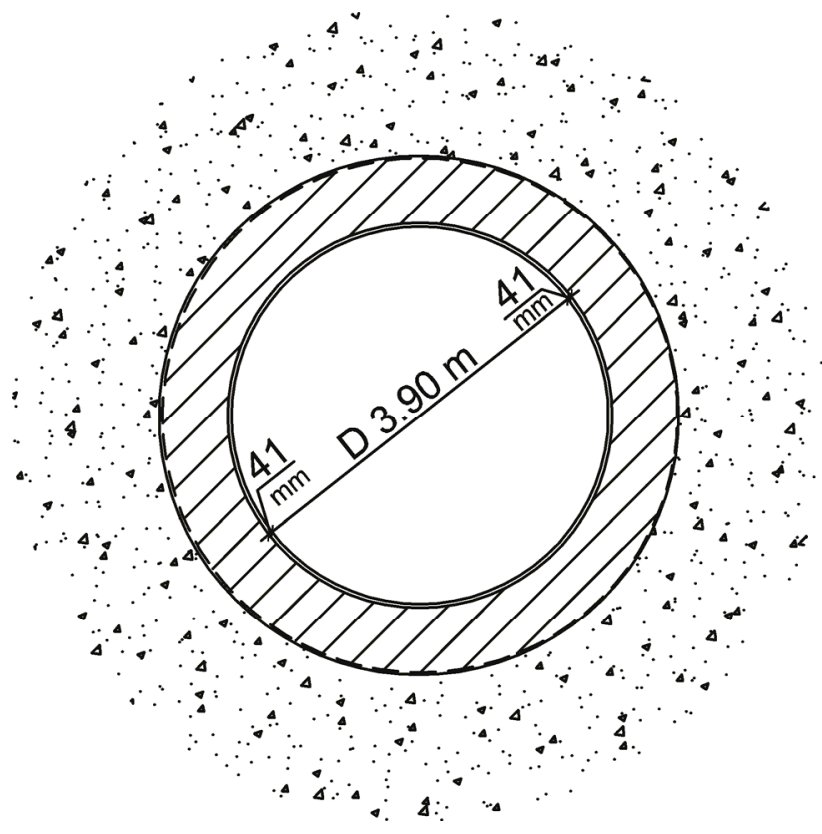

Figure 2: Cross-section of the steel penstock - Variant 1, the first pipe section.

\subsection{Vertical penstock}

The vertical penstock is designed to be $784.06 \mathrm{~m}$ long steel liner (see Figure 3). Steel S690 Q was considered. Input data comprise internal diameters $D$ from $3.20 \mathrm{~m}$ to $4.00 \mathrm{~m}$, pipe section lengths $L_{\text {sect }}$ from $9.00 \mathrm{~m}$ to $81.00 \mathrm{~m}$, the 
corrosion allowance cor $=0.2 \mathrm{~cm}$, yield strength $f_{y}=65.0 \mathrm{kN} / \mathrm{cm}^{2}$, safety factor relative to the internal water pressure $C_{i p}=1.50$, safety factor relative to the external water pressure $C_{e p}=1.80$, maximal internal water pressure $p_{i n}=949.20$ $\mathrm{kN} / \mathrm{cm}^{2}$ (94.92 bars) and maximal external water pressure $p_{e x}=782.90 \mathrm{kN} / \mathrm{cm}^{2}$ (78.29 bars).

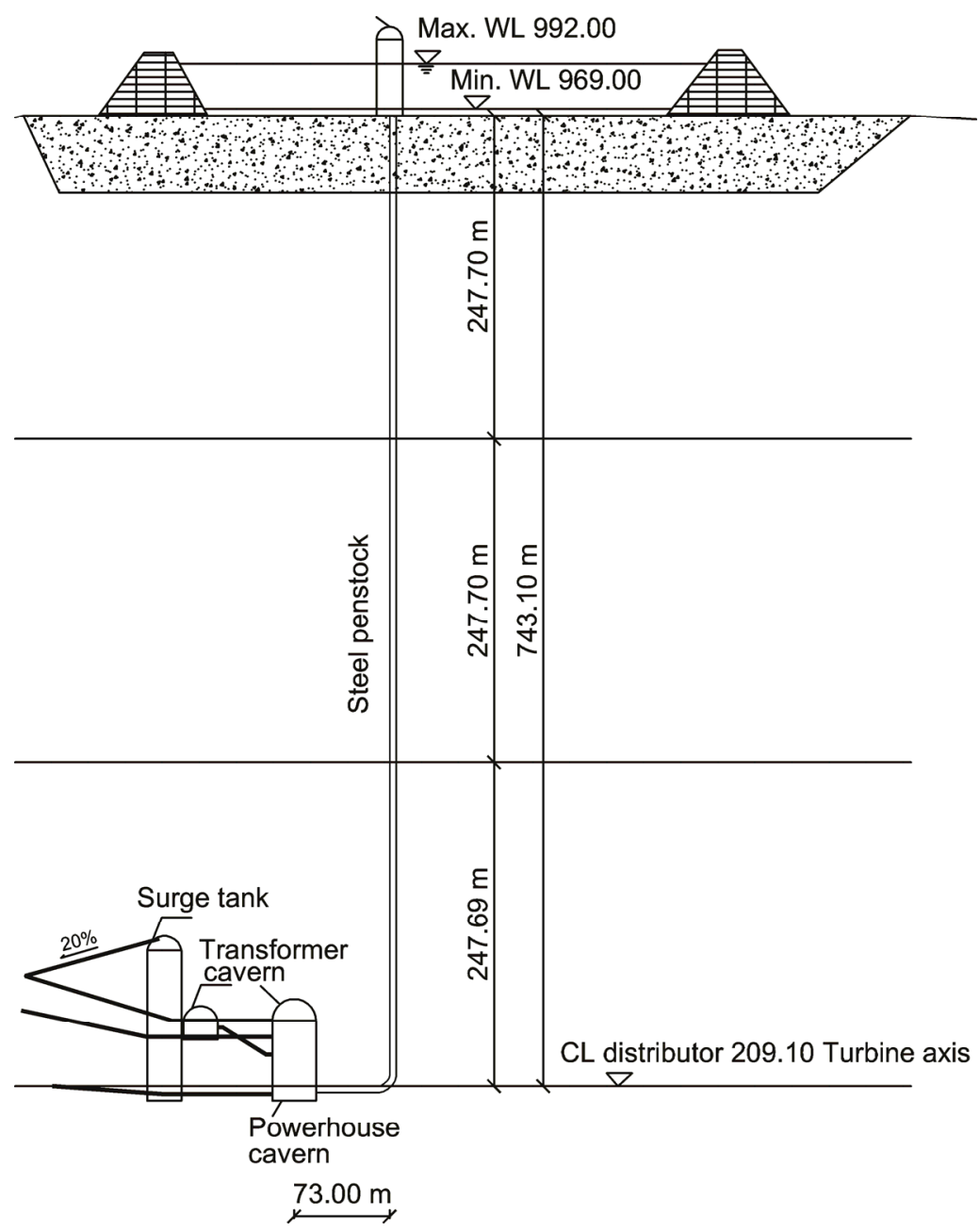

Figure 3: The vertical penstock.

16 different pipe sections of different diameters and lengths were optimized. The optimal result represents the obtained penstock's minimal mass of 3165.34 tons and the calculated wall thicknesses from $18 \mathrm{~mm}$ to $68 \mathrm{~mm}$ (see Table 2). A cross-section through the first pipe section is shown in Figure 4. 
Table 2: Optimized mass of the penstock - the vertical penstock.

\begin{tabular}{|c|c|c|c|c|c|c|}
\hline $\mathrm{x} \quad(\mathrm{m})$ & $\mathrm{p}_{\text {in }}(\mathrm{m})$ & $\mathrm{p}_{\mathrm{ex}}(\mathrm{m})$ & $\mathrm{D}(\mathrm{m})$ & $\mathrm{t}(\mathrm{mm})$ & $\mathrm{L}_{\text {sect }}(\mathrm{m})$ & $\Sigma \mathrm{G}(\mathrm{kg})$ \\
\hline 81.00 & 883.00 & 733.90 & \multirow{4}{*}{3.20} & 65 & 54.00 & 282624 \\
\hline 135.00 & 817.60 & 679.90 & & 62 & 54.00 & 269332 \\
\hline 189.00 & 752.10 & 625.90 & & 55 & 54.00 & 238411 \\
\hline 243.00 & 686.70 & 571.90 & & 54 & 36.66 & 158863 \\
\hline \multicolumn{6}{|c|}{ Lower part : } & 1393140 \\
\hline 279.66 & 642.20 & 535.20 & \multirow{5}{*}{3.40} & 57 & 54.00 & 262414 \\
\hline 333.66 & 576.70 & 481.20 & & 53 & 54.00 & 243716 \\
\hline 387.66 & 511.30 & 427.20 & & 48 & 54.00 & 220405 \\
\hline 441.66 & 445.80 & 373.20 & & 45 & 54.00 & 206450 \\
\hline 495.66 & 380.40 & 319.20 & & 41 & 31.70 & 110292 \\
\hline \multicolumn{6}{|c|}{ Middle part: } & 1043277 \\
\hline 527.36 & 341.90 & 287.50 & \multirow{5}{*}{3.60} & 41 & 54.00 & 198800 \\
\hline 581.36 & 276.50 & 233.50 & & 36 & 54.00 & 174316 \\
\hline 635.36 & 211.00 & 179.50 & & 31 & 54.00 & 149899 \\
\hline 689.36 & 145.60 & 125.50 & & 27 & 54.00 & 130414 \\
\hline 743.36 & 78.10 & 69.50 & & 21 & 31.70 & 59446 \\
\hline 775.06 & 39.80 & 37.80 & 4.00 & 18 & 9.00 & 16052 \\
\hline \multicolumn{6}{|c|}{ Upper part : } & \multirow{2}{*}{$\begin{array}{r}728927 \\
3165344 \\
\end{array}$} \\
\hline \multicolumn{6}{|c|}{ Penstock total : } & \\
\hline
\end{tabular}

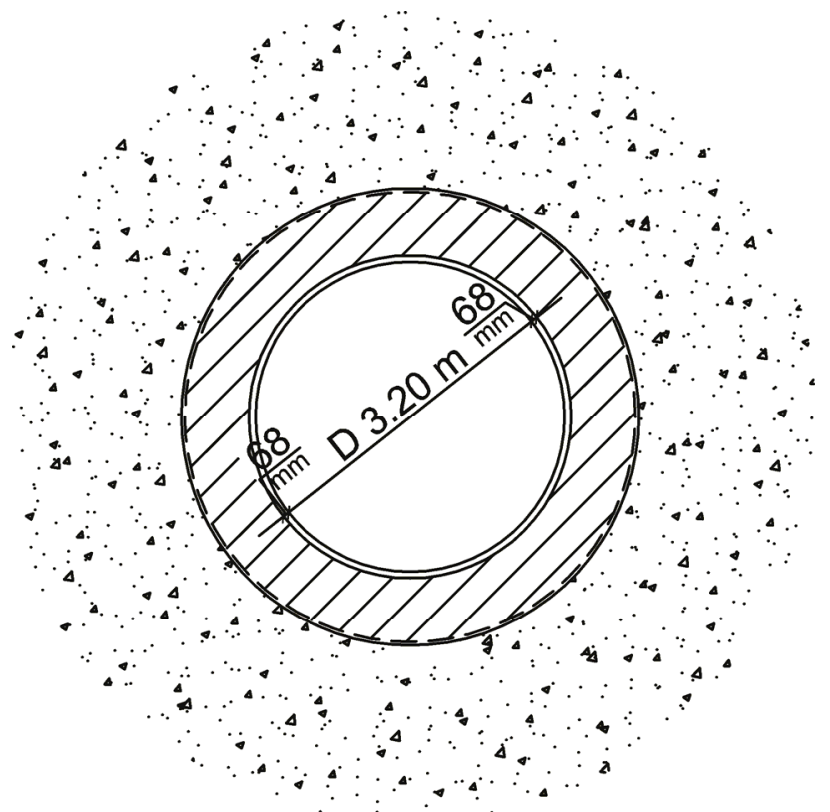

Figure 4: Cross-section of the first pipe section - the vertical penstock. 


\section{Conclusions}

The paper presents the optimization of steel penstock, designed to be built in bored tunnel. The optimization was performed by the non-linear programming (NLP) approach. For this purpose, the NLP optimization model PIPEOPT was developed. The model comprises the mass objective function, which is subjected to design and dimensioning constraints. Numerical example of the penstock optimization, planed to be made for the pumped storage hydroelectric power plant Kozjak in Slovenia, demonstrates the efficiency of the presented NLP optimization approach.

\section{References}

[1] C.E.C.T., Recommendations for the design, manufacture and erection of steel penstocks of welded construction for hydro electric installations, European Committee for boilermaking and kindred steel structures, Prepared by the "Penstock" Section, 1979.

[2] Brooke, A., Kendrick, D. and Meeraus, A., GAMS - A User's Guide, Scientific Press, Redwood City, CA, 1988.

[3] Močnik, I., Kimovec, J., Penstock dimensioning, 3. Civil construction design, Penstock, Kozjak PSP, IBE Ljubljana, 2011.

[4] Močnik, I., Technical Report, 3. Civil construction design, 3/18 Penstock cavern type, Kozjak PSP, IBE Ljubljana, 2012.

[5] Kravanja, S., The optimization of penstock with the recommendations for the design of steel liner and the collaboration of the rock, The recommendations for the dimensioning and optimization of steel penstock, (Optimizacija cevovoda $\mathrm{z}$ izhodišči za načrtovanje jeklene obloge in sodelovanja hribine, Izhodišča za dimenzioniranje in optimizacijo jeklenega cevovoda), Kozjak PSP, Faculty of Civil Engineering, University of Maribor, 2011.

[6] Kravanja, S., The optimization of penstock with the recommendations for the design of steel liner and the collaboration of the rock, Variant the Vertical penstock, The recommendations for the dimensioning and optimization of steel penstock, (Optimizacija cevovoda $\mathrm{z}$ izhodišči za načrtovanje jeklene obloge in sodelovanja hribine, Varianta vertikalni cevovod - kaverna, Izhodišča za dimenzioniranje in optimizacijo jeklenega cevovoda), Kozjak PSP, Faculty of Civil Engineering, University of Maribor, 2012.

[7] Drudd, A.S., CONOPT - A Large-Scale GRG Code. ORSA Journal on Computing, 6 (2), pp. 207-216, 1994. 